Egyptian

Orthodontic Journal

\title{
COMPARING DIFFERENT PORCELAIN SURFACE POLISHING TECHNIQUES AFTER ORTHODONTIC BRACKETS DEBONDING
}

\author{
Hany Salah Eid, ${ }^{1}$ \\ Nasser Hussein, ${ }^{2}$
}

\section{ABSTRACT:}

Objectives: The present study was designed to investigate different polishing techniques used to restore feldspathic porcelain surface regarding surface roughness after debonding of orthodontic brackets. Methods: Metal discs of $1 \mathrm{~cm}$ diameter and $1 \mathrm{~mm}$ thickness $(n=85)$ were prepared from Wiron 99 non-precious alloy (BEGO Bremer Goldschägerei with Herbst Gm6H HaZ Co. Bremen. Germany). The discs were veneered from one side by $1 \mathrm{~mm}$ thickness Vita VMMK Master feldspathic porcelain (Nita zhan fabric $\mathcal{H}$. Rauter GmbH \& L Co. KG. Germany). Five of these intact samples composed the control group (C). Orthodontic metal brackets were bonded at the center of each of the remaining discs (3MM, Unitek), and then discs were water stored for 30 days before debonding. Brackets were debonded using bracket removing pliers, and resin was removed with a sharp chisel. The prepared specimens $(n=80)$ were divided into 4 groups $(n=20)$ according to the surface treatment they were to receive: (G1): using (Shofu, USA) porcelain veneer jkit, (G2): using (Ultradent, USA) porcelain finishing kit, (G3): using (Sof-lex 3M, USA) porcelain polishing kit, and (G4): no surface treatment. The surface roughness (Ra) was

1- Lecturer of Orthodontics, Faculty of Dentistry, Misr University for Science and Technology, $6^{\text {th }}$ of October city, Egypt.

2- Lecturer of fixed Prosthodontics, Faculty of Dentistry, Misr University for Science and Technology, $6^{\text {th }}$ of October city, Egypt. 
Egyptian

Orthodontic Journal

evaluated quantitatively using USB Digital microscope with a built-in camera (Scope Capture Digital Microscope, Guangdong, China). WSXM software was used to calculate root mean square (RSMS) of the average height of every specimen expressed in $(\mu \mathrm{m})$ in each group including control samples. Data was analyzed with 2-way ANOVA followed by student's t test $(p<0.05)$.

Results: The polishing techniques affected surface roughness significantly $(\mathcal{P}<0.001)$, with significant higher $R a$ values than the glazed baseline porcelain. The surface roughness values were not statistically different among the polishing groups ( $P>0.05)$.

Conclusion: The results of this study indicated that the tested polishing techniques improved the surface roughness greatly, however, were not able to reestablish the original glazed porcelain smoothness.

\section{INTRODUCTION}

The past few years, the age limit for orthodontic treatment has increased; as a consequence, more adult patients are now being treated orthodontically to improve the quality of their lives. Adult patients however, are known to have more dental work done to them than younger individuals seeking orthodontic treatment. Unfortunately, among the most frequent dental work seen in that older group of age, is prosthetic work, that when encountered with orthodontic treatment, damage is not a seldom consequence, especially ceramic materials, since it is commonly used as a restorative material in the replacement of a lost or damaged tooth or an unaesthetic enamel, as well as its superior durability, and biocompatibility. ${ }^{1}$

The conventional orthodontic bonding system does not provide enough bond strength to porcelain to withstand orthodontic forces. Thus, to increase the bond strength of orthodontic brackets to porcelain restorations, several chemo-mechanical alternatives are available. These methods are bonding to glazed porcelain with a coupling agent (silane), 
Egyptian

Orthodontic Journal

deglazing the porcelain by roughening the surface with diamond burs, air-particle abrasion (APA) with aluminum oxide, and chemical preparation of the porcelain with acids (phosphoric acid, hydrofluoric acid [HFA], or acidulated phosphate fluoride). ${ }^{2-6}$

Possible outcomes of the altered porcelain surface are but not limited to; reduction in the strength of the porcelain restoration, ${ }^{8}$ increased rate of plaque accumulation, thus producing gingival inflammation and adverse soft tissue reactions. ${ }^{9}$ Therefore, it is mandatory to prevent or reduce damage to the porcelain caused by roughening during surface conditioning, for these restorations, are supposed to remain in the mouth for a long time following orthodontic treatment. ${ }^{3}$ knowing that, a clinically reliable bond between the bracket and the porcelain is impossible without mechanical or chemical roughening of porcelain surface. ${ }^{2,3,6,7}$

Glazing of porcelain surface in general covers the porosity on the fired porcelain, thus enhances resistance to fracture and the ceramic is rendered less prone to wear. A smooth porcelain surface is obtained by applying a glaze that consists of colorless glass powder layer over the porcelain. ${ }^{8}$ However, after orthodontic treatment, the debonding of brackets breaks the glaze layer creating a rough surface. Therefore, in order to restore a glossy surface, refinishing or polishing after these procedures is mandatory. Removing ceramic restorations and reglazing them under laboratory conditions is not practical in orthodontic practice, since subjecting the porcelain to another firing cycle is time-consuming and requires the removal of the restoration from the prepared tooth, therefore, both the restoration and tooth are subjected to damage. ${ }^{9}$ Hence, intraoral polishing of the restorations is an attractive alternative. Chairside porcelain refinishing is an easy method for the clinician that also provides infection control by eliminating repeated laboratory procedures. $^{10}$

Surface roughness $(\mathrm{Ra})$ refers to the finer irregularities of the surface texture that usually result from the action of the production process or material condition and is measured in micrometers $(\mu \mathrm{m}) .{ }^{11}$ It is known that a smooth surface is desirable to reduce retention of bacteria and to have a glossy appearance. ${ }^{12}$ It was hypothesized that porcelain bonded with orthodontic brackets and then debonded would exhibit significant 
surface alterations relative to the prebonding measurements. But it was claimed however that the surface could be restored using porcelain polishing kits for polishing porcelain surface to return it to its prebonded glazed condition. ${ }^{13,14}$

The present in-vitro study was designed to investigate and compare 3 different commercial chairside polishing techniques, used to restore feldspathic porcelain surface, regarding surface roughness after debonding of orthodontic brackets.

\section{MATERIALS AND METHODS}

A total of 85 metal discs (Wiron 99 non-precious alloy) of $10 \mathrm{~mm}$ diameter and $1 \mathrm{~mm}$ thickness were cast. The discs were then veneered from one side according to the manufacturer's instructions by porcelain (Vita porcelain VMK MasterFeldspathic) to form ceramo-metallic discs. The porcelain surface of the ceramometallic discs was progressively finished with 150, 220, 320, 400, 600, 1000, and 1200 grit silicon carbide papers, and ultrasonically cleansed for 10 minutes in distilled water before glazing (Fig 1). Five randomly selected samples of glazed porcelain were selected to measure their surface roughness $(\mathrm{Ra})$ to represent the intact control group $(C)(n=5)$.

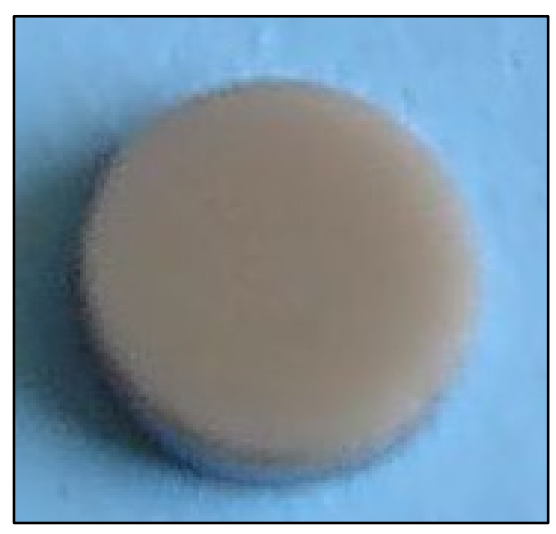

Fig 1: Ceramo-metallic disc 
Egyptian

Orthodontic Journal

\section{Roughness Measurement Methodology:}

An optical method was used to fulfill the need for quantitative characterization of surface topography without contact. Specimens were photographed using USB Digital microscope with a built-in camera (Scope Capture Digital Microscope, Guangdong, China) connected with an IBM compatible personal computer using a fixed magnification of 50X. The bitmap images were recorded with a resolution of $1280 \times 1024$ pixels per image. Digital microscope images were cropped to 487 x 348 pixels using Microsoft office picture manager to specify/standardize areas of roughness measurements. The cropped images were analyzed using WSxM software. ${ }^{15}$ Within the WSxM software, all limits, sizes, frames and measured parameters were expressed in pixels, then system calibration was performed by comparing an object of known size (a ruler in this study) with a scale generated by the software, to convert the pixels into absolute real world units. Subsequently, a 3D image of the surface profile of the specimens was created. WSxM software calculated the root mean square (RMS) of the average height of every specimen, expressed in $\mu \mathrm{m}$, which can be assumed as a reliable index of surface roughness $(\mathrm{Ra}){ }^{16}$

\section{Porcelain Surface Bonding and Debonding Techniques:}

The porcelain surface of all the remaining prepared samples $(n=80)$ were etched with Porcelain etch $4 \%$ hydrofluoric acid gel (Ultradent products Inc. USA) for 4 minutes, rinsed for $1 \mathrm{~min}$. and then air-dried. Ultradent silane coupling agent was applied on the surface of the etched discs and left for one minute then air dried. Metal brackets were bonded to surfaces using Transbond XT (3M Unitek, Monrovia, Calif) (Fig 2). The excess resin was removed, and the adhesive was light cured for 40 seconds using conventional halogen (Ortholux XL 3000, $3 \mathrm{M}$ Unitek). Bonded porcelain samples were stored in water at $37^{\circ} \mathrm{C}$ for 24 hours before debonding. Brackets were debonded by hand rather than using a testing machine in shear or tension to simulate clinical procedures. Bond strength was not investigated, as multiple laboratory studies had previously found clinically adequate bond strengths (6-8 MPa or greater). ${ }^{17}$ The brackets were debonded using bracket removing pliers (\#098-SL; Orthopli Corp, Philadelphia, Pa, USA). 


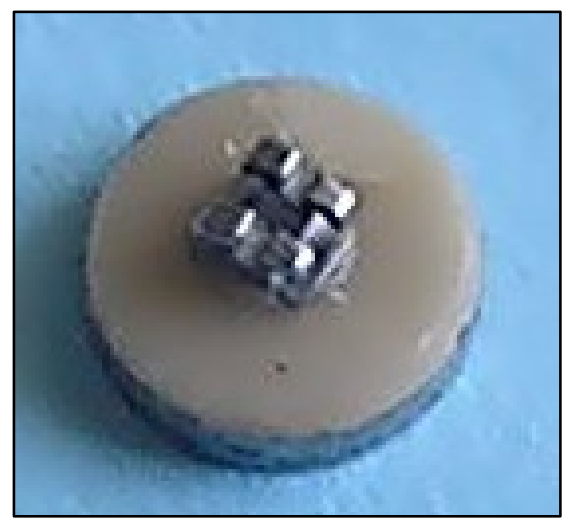

Fig.2: Orthodontic bracket bonded to porcelain surface

Each debonded sample was then mounted onto a specially designed jig of a computer controlled materials testing machine (Model LRX-plus; Lloyd Instruments Ltd., Fareham, UK), where a specially constructed chisel shaped blade was mounted, loaded with $98 \mathrm{~N}(10 \mathrm{Kg})$ shearing force to remove the remnants of bonding resin.

Twenty randomly selected debonded porcelain samples were selected, to measure their surface roughness $(\mathrm{Ra})$ as described above to represent group $4(\mathrm{G} 4)(n=20)$. The remaining samples $(n=60)$, were randomly devided into 3 groups $(n=20)$, according to the surface treatment they were to receive: (G1): using (Shofu, USA) porcelain veneer kit, (G2): using (Ultradent, USA) porcelain finishing kit, (G3): using (Sof-lex 3M, USA) porcelain polishing kit. For all the refinishing systems applied on the 60 samples, a low speed hand piece was used, rotating at 20,000 RPM with 2.4 atomic air pressure, mounted to a special device to ensure standardization of refinishing pressure,${ }^{18}$ direction and rate to which the samples were subjected (Fig 3). Refinishing procedure was performed until the porcelain surface appeared smooth to the eye. After refinishing of all the 60 samples in the 3 groups, porcelain surface roughness $(\mathrm{Ra})$ was measured as described above. 


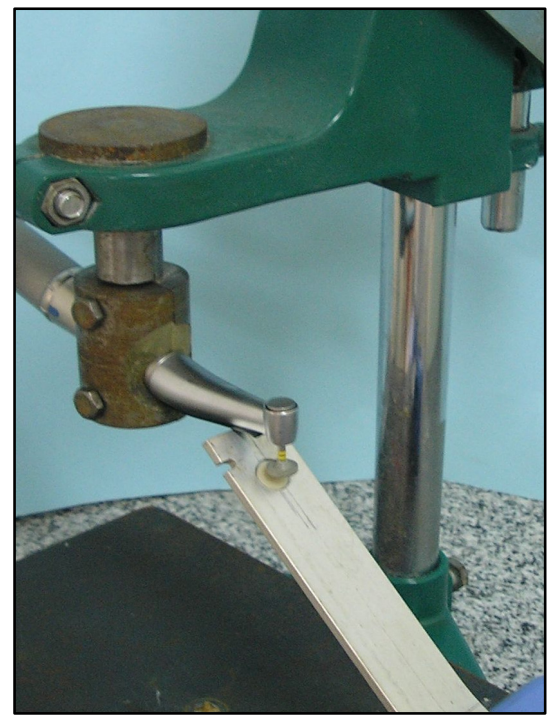

Fig 3: Refinishing standardization device

\section{Statistical Methods:}

Analysis of data was done using SPSS version 10, range (minimum maximum), mean value and standard deviation as well as median value, were used for summarizing data. Two way ANOVA test was used for comparing groups, student's t test was used for comparing mean values of two groups. Significant results was considered if $p<0.05$, high significant results was considered if $\mathrm{p}<0.01$.

\section{RESULTS}

There was high statistical significant difference between all studied groups; (G1-G4) and control group $(\mathrm{C})(\mathrm{p}<0.01)$, where (G4) group, that received no surface treatment, showed the highest $(\mathrm{Ra})$ values relative to control group, followed by Shofu group (G1), then Sof-Lex group (G3), while the least $(\mathrm{Ra})$ value compared to control group was for Ultradent group (G2) (table 1). However, there was no statistical significant difference between the studied groups; (G1-G3) with each other $(p>0.5)$ (table2). Significant difference was found when comparing every group of the tested materials with (G4) group $(\mathrm{p}<0.05)$ (table3). 
Table (1): Difference between the studied groups and control group:

\begin{tabular}{|l|l|l|l|l|l|}
\hline $\begin{array}{c}\text { ANOVA } \\
\text { test }\end{array}$ & \multicolumn{1}{|c|}{$\begin{array}{c}\text { Control } \\
(\mathbf{C})\end{array}$} & \multicolumn{1}{|c|}{$\begin{array}{c}\text { Shofu } \\
(\mathbf{G 1})\end{array}$} & $\begin{array}{c}\text { Ultradent } \\
(\mathbf{G} 2)\end{array}$ & $\begin{array}{c}\text { Sof-lex } \\
(\mathbf{G 3})\end{array}$ & $\begin{array}{c}\text { No surface ttt. } \\
\text { (G4) }\end{array}$ \\
\hline Range & $0.03-0.038$ & $0.059 \pm 0.006$ & $0.055 \pm 0.027$ & $0.056 \pm 0.006$ & $0.066 \pm 0.008$ \\
\hline Mean \pm SD & $0.033 \pm 0.003$ & $0.052-0.069$ & $0.031-0.107$ & $0.049-0.065$ & $0.052-0.079$ \\
\hline Median & 0.033 & 0.06 & 0.046 & 0.056 & 0.066 \\
\hline $\begin{array}{l}\text { ANOVA } \\
\text { test value }\end{array}$ & \multicolumn{5}{|c|}{$\mathrm{F}=33.79$} \\
\hline P value & \multicolumn{5}{|c|}{0.0000} \\
\hline
\end{tabular}

\begin{tabular}{|c|c|c|}
\hline Student's t test & Control group (C) & Shofu(G1) \\
\hline Range & $0.03-0.038$ & $0.059 \pm 0.006$ \\
\hline Mean \pm SD & $0.033 \pm 0.003$ & $0.052-0.069$ \\
\hline Median & 0.033 & 0.06 \\
\hline Student's t test value & \multicolumn{2}{|c|}{9.29} \\
\hline \multirow[t]{2}{*}{$\mathrm{P}$ value } & \multicolumn{2}{|c|}{0.0001} \\
\hline & & Ultradent(G2) \\
\hline Range & $0.03-0.038$ & $0.055 \pm 0.027$ \\
\hline Mean \pm SD & $0.033 \pm 0.003$ & $0.031-0.107$ \\
\hline Median & 0.033 & 0.046 \\
\hline Student's t test & \multicolumn{2}{|c|}{15.96} \\
\hline$P$ value & \multicolumn{2}{|c|}{0.0001} \\
\hline & & Sof-lex(G3) \\
\hline Range & $0.03-0.038$ & $0.056 \pm 0.006$ \\
\hline Mean \pm SD & $0.033 \pm 0.003$ & $0.049-0.065$ \\
\hline Median & 0.033 & 0.056 \\
\hline Student's t test & \multicolumn{2}{|c|}{8.22} \\
\hline$P$ value & \multicolumn{2}{|c|}{0.0001} \\
\hline
\end{tabular}

\begin{tabular}{|l|c|c|}
\hline & & No surface ttt. (G4) \\
\hline Range & $30.03-0.038$ & $0.066 \pm 0.008$ \\
\hline Mean \pm SD & $0.033 \pm 0.00$ & $0.052-0.079$ \\
\hline Median & 0.033 & 0.066 \\
\hline Student's t test & \multicolumn{2}{|c|}{8.94} \\
\hline P value & \multicolumn{2}{|c|}{0.0001} \\
\hline
\end{tabular}


Egyptian

Orthodontic Journal

Table (2): Difference between each of the groups representing different refinishing techniques:

\begin{tabular}{|c|c|c|}
\hline & Shofu(G1) & Ultradent(G2) \\
\hline Range & $0.052-0.069$ & $0.055 \pm 0.027$ \\
\hline Mean $\pm \mathrm{SD}$ & $0.059 \pm 0.006$ & $0.031-0.107$ \\
\hline Median & 0.06 & 0.046 \\
\hline Student's t test & \multicolumn{2}{|c|}{1.64} \\
\hline $\mathrm{P}$ value & \multicolumn{2}{|c|}{0.1112} \\
\hline & Shofu(G1) & Sof-lex(G3) \\
\hline Range & $0.052-0.069$ & $0.056 \pm 0.006$ \\
\hline Mean \pm SD & $0.059 \pm 0.006$ & $0.049-0.065$ \\
\hline Median & 0.06 & 0.056 \\
\hline Student's t test & \multicolumn{2}{|c|}{1.58} \\
\hline $\mathrm{P}$ value & \multicolumn{2}{|c|}{0.1213} \\
\hline & Ultradent(G2) & Sof-lex(G3) \\
\hline Range & $0.031-0.107$ & $0.056 \pm 0.006$ \\
\hline Mean \pm SD & $0.055 \pm 0.027$ & $0.049-0.065$ \\
\hline Median & 0.046 & 0.056 \\
\hline Student's t test & \multicolumn{2}{|c|}{0.82} \\
\hline $\mathrm{P}$ value & \multicolumn{2}{|c|}{0.4171} \\
\hline
\end{tabular}

Table (3): Difference between studied groups and the group with no surface treatment:

\begin{tabular}{|c|c|c|}
\hline & Ultradent(G2) & No surface ttt. (G4) \\
\hline Range & $70.031-0.107$ & $0.066 \pm 0.008$ \\
\hline Mean \pm SD & $0.055 \pm 0.02$ & $0.052-0.079$ \\
\hline Median & 0.046 & 0.066 \\
\hline Student's t test & \multicolumn{2}{|c|}{2.41} \\
\hline $\mathrm{P}$ value & \multicolumn{2}{|c|}{0.0241} \\
\hline & Sof-lex(G3) & \\
\hline Range & $0.049-0.065$ & $0.066 \pm 0.008$ \\
\hline Mean \pm SD & $0.056 \pm 0.006$ & $0.052-0.079$ \\
\hline Median & 0.056 & 0.066 \\
\hline Student's t test & \multicolumn{2}{|c|}{4.47} \\
\hline $\mathrm{P}$ value & \multicolumn{2}{|c|}{0.0001} \\
\hline & Shofu(G1) & \\
\hline Range & $0.052-0.069$ & $0.066 \pm 0.008$ \\
\hline Mean \pm SD & $0.059 \pm 0.006$ & $0.052-0.079$ \\
\hline Median & 0.06 & 0.066 \\
\hline Student's t test & \multicolumn{2}{|c|}{3.13} \\
\hline $\mathrm{P}$ value & \multicolumn{2}{|c|}{0.0031} \\
\hline
\end{tabular}


Egyptian

Orthodontic Journal

\section{DISCUSSION}

The efficiency of different porcelain polishing kits were compared in this study, the selected materials were among a variety of commercially used dental porcelain refinishing systems that can be used intraorally. In this study, there was no doubt that surface roughness of refinished porcelain has been improved using each of the tested kits, compared to the dramatic increase in surface roughness noticed after debonding of orthodontic brackets (tables 1\&3). However, in spite of the improvement noticed, none of the kits was able to reestablish the original glaze of the porcelain surface presented in the unaltered control group (figure 1). Even though the Ultradent kit showed the best surface roughness improvement, still it failed to statistically score a significant difference that could lead to its preference compared with the other two kits (table 2).

Many studies have debated over the effectiveness of porcelain polishing systems, concluding that the final ceramic surfaces obtained with commercially available refinishing kits are comparable to those of glazed surfaces. ${ }^{19,20}$ However; some authors have reported that polishing systems cannot recreate a surface that is as smooth as the original glaze. ${ }^{21-23}$ In a previous study by Campbell, ${ }^{24}$ the Shofu polishing system was not able to reproduce porcelain glaze smoothness in a deglazed porcelain surface. Goldstein et $\mathrm{al}^{25}$ evaluated five different porcelain polishing systems, and found four of them clinically acceptable for polishing altered porcelain surface. It should be noticed that these studies did not debond orthodontic brackets from the surface, only simulated prosthetic clinical surface alterations. Knowing that it has been found in earlier studies, that the use of the Sof-Lex system, obtained the best results for several types of porcelain surface refinishing. ${ }^{26-28}$ Furthermore, it was reported that the flexible polishing discs of the Sof-Lex system is advantageous when attempting to polish flat and convex porcelain surfaces. $^{28}$

Previous studies have criticized the evaluation of smoothness of porcelain surfaces from scanning electron microscope photomicrographs 
Fig.(1): Mean value off surface roughness for the studied groups

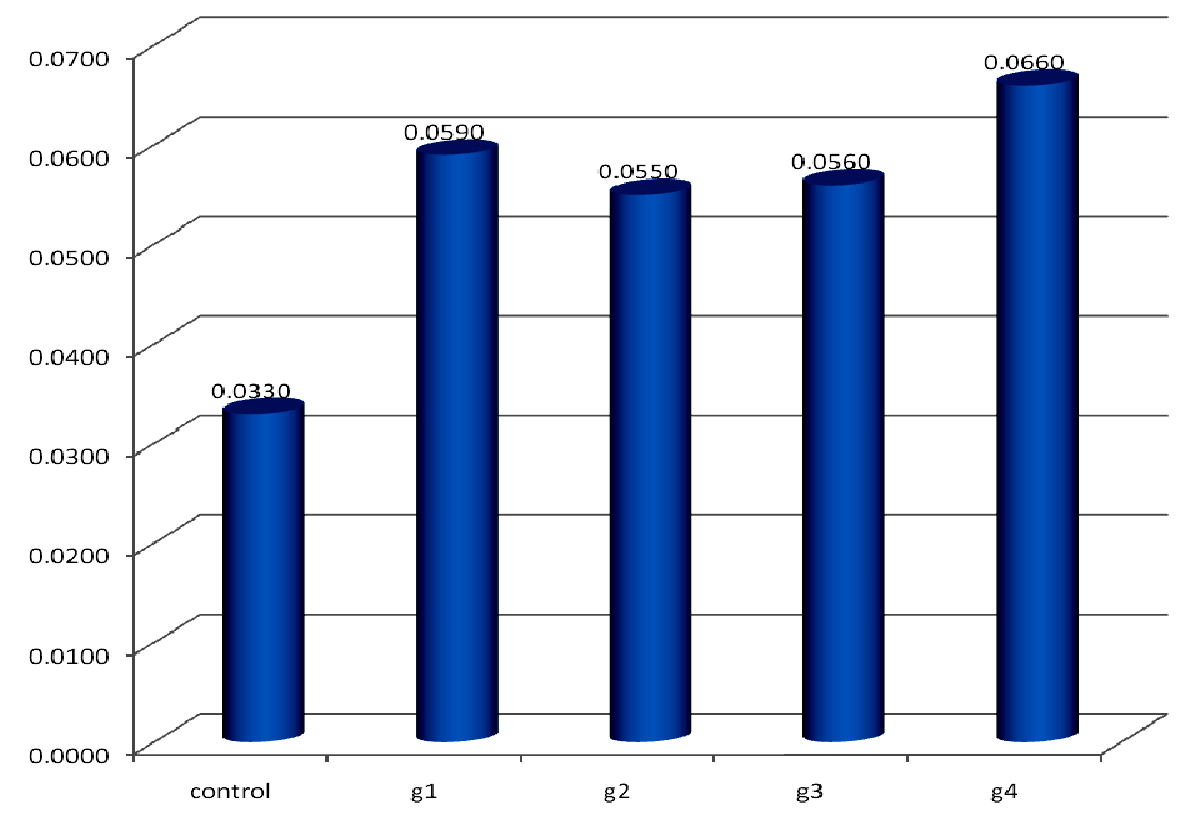

that was used in this study, and described it as unreliable and subjective. ${ }^{20}$ Quantitative evaluation using a profilometer was suggested, which determines roughness by the undulations of the profile relative to some baseline. However, it was reported that some profilometer measurements of ceramic surfaces may be misinterpreted because of the pores in the ceramic material, ${ }^{29}$ since the manufacturing techniques produce pores within the ceramic, and the removal of the glaze causes them to open up..$^{8}$ AFM (Atomic Force Microscope) analysis is another alternative method that uses multiple mechanical scans in high resolution. $^{30}$

Based on the findings of the present study, the refinishing kits tested seem to be successful regarding improving the rough porcelain surfaces produced after orthodontic appliances have been removed, but failed to reproduce the original glazed surface before bonding of the appliance. 
Egyptian

Orthodontic Journal

\section{CONCLUSIONS}

- The polishing methods used in the study significantly improved the surface roughness, but failed to restore the porcelain to the original glazed surface found prior to bonding of orthodontic brackets.

- There were no statistically significant differences in porcelain surface roughness among the three porcelain refinishing systems.

\section{REFERENCES}

1- karan S. and Toroglu M.S. Porcelain refinishing with two different polishing systems after orthodontic debonding. Angle Orthod 2008. 78(5):947-53.

2- Schmage, P., I. Nergiz, W. Herrman, and M. Özcan. Influence of various surface-conditioning methods on the bond strength of metal brackets to ceramic surfaces. Am J Orthod Dentofacial Orthop 2003. 123:540-546.

3- Özcan, M., P. K. Vallittu, T. Peltomäki, M. Huysmans, and W. Kalk. Bonding polycarbonate brackets to ceramic: effects of substrate treatment on bond strength. Am J Orthod Dentofacial Orthop 2004. 126:220-227.

4- Smith, G. A., P. McInnes-Ledoux, W. R. Ledoux, and R. Weinberg. Orthodontic bonding to porcelain-bond strength and refinishing. Am J Orthod Dentofacial Orthop 1988. 94:245-252.

5- Zachrisson, YØ, B. U. Zachrisson, and T. Büyükyılmaz. Surface preparation for orthodontic bonding to porcelain. Am J Orthod Dentofacial Orthop 1996. 109:420-430.

6- Harari, D., S. Shapira-Davis, I. Gillis, I. Roman, and M. Redlich. Tensile bond strength of ceramic brackets bonded to porcelain facets. Am J Orthod Dentofacial Orthop 2003. 123:551-554.

7- Huang, T. H. and C. T. Kao. The shear bond strength of composite brackets on porcelain teeth. Eur J Orthod 2001. 23:433-439.

8- Anusavice, K. J. and R. W. Phillips. Eds. Phillip's Science of Dental Materials. 11th ed. St Louis, MO: Elsevier; 2003:660-672. 
9- Nebbe, B. and E. Stein. Orthodontic brackets bonded to glazed and deglazed porcelain surfaces. Am J Orthod Dentofacial Orthop 1996. 109:431-436.

10- Sarikaya I. and Guler A. Effects of different polishing techniques on the surface roughness of dental porcelains. J. Appl. Oral Sci. vol. 18 no. 12010.

11- Paravina RD, Powers JM. Esthetic color training in dentistry. Saint Louis: Mosby; 2004. p.43-4.

12- Craig RG, Powers JM, Wataha JC. Dental Materials: properties and manipulation. Saint Louis: Mosby; 2004. p.113.

13- Ancowitz S, Torres T, Rostami H. Texturing and polishing: The final attempt at value control. Dent Clin North Am. 1998; 42(4):607-12.

14- Jefferies SR. The art and science of abrasive finishing and polishing in restorative dentistry. Dent Clin North Am. 1998; 42(4); 613-27.

15- Horcas I, Fernandez R, Gomez JM, Colchero J, Gomez-Herrero J, and Baro AM, Review of Scientific Instruments. 2007; 78; 013705.

16- Kakaboura A, Fragouli M, Rahiotis C, et al. Evaluation of surface characteristics of dental composites using profilometry, scanning electron, atomic force microscopy and gloss-meter. J Mater Sci Mater Med 2007; 18: 155-63.

17- Reynolds, I. R. A review of orthodontic bonding. Br J Orthod 1975. 2:171-178.

18- Mona H, Amina H, Gihan F . Effect of ferrule design, post type and functional loading on the fracture strength and coronal leakage of endodontically treated maxillary premolars. PHD thesis, Ain-Shams University, 2012.

19- Eustaquio, R., L. D. Garner, and B. K. Moore. Comparative tensile strengths of brackets bonded to porcelain with orthodontic adhesive and porcelain repair systems. Am J Orthod Dentofacial Orthop 1988. 94:421-425.

20- Winchester, L. and M. Orth. Direct orthodontic bonding to porcelain: an in vitro study. Br J Orthod 1991. 18:299-308. 
21- Chu, F. C, N. Frankel, and R. J. Smales. Surface roughness and flexural strength of self-glazed, polished, and reglazed In-Ceram/Vitadur Alpha porcelain laminates. Int J Prosthodont 2000. 1:66-71.

22- Pattersson, C. J., A. C. McLundie, D. R. Stirrups, and W. G. Taylor. Efficacy of a porcelain refinishing system in restoring surface finish after grinding with fine and extra fine diamond burs. J Prosthet Dent 1992. 3:402-406.

23- Sarac, Y. S., S. Elekdag-Turk, D. Sarac, and T. Turk. Surface conditioning methods and polishing techniques effect on surface roughness of a feldspar ceramic. Angle Orthod 2007. 4:723-728.

24- Campbell, S. D. Evaluation of surface roughness and polishing techniques for new ceramic materials. J Prosthet Dent 1989. 61:563-568.

25- Goldstein, G. R., B. R. Barnhard, and B. Penugonda . Profilometer, SEM, and visual assessment of porcelain polishing methods. J Prosthet Dent 1991. 65:627-634.

26- Hulterström, A. K. and M. Bergman. Polishing systems for dental ceramics. Acta Odontol Scand 1993. 51:229-234.

27- Martinez-Gomis, J., J. Bizar, J. M. Anglada, J. Samso, and M. Peraire. Comparative evaluation of four finishing systems on one ceramic surface. Int J Prosthodont 2003. 16:74-77.

28- Kou, W., M. Molin, and G. Sjögren. Surface roughness of five different dental ceramic core materials after grinding and polishing. J Oral Rehabil 2006. 33:117-124.

29- Tholt de Vasconcellos, B., W. G. Miranda-Junior, R. Prioli, J. Thompson, and M. Oda. Surface roughness in ceramics with different finishing techniques using atomic force microscope and profilometer. Oper Dent 2006. 4:442-449.

30- Cury- Saramago Ade A. et al. Ceramic surface polishing techniques after removal of orthodontic adhesive. Angle Orthod. 2009 Jul; 79 (4): 790-5. 